\title{
Music-therapy Study of Music's Preferences and Regulation Properties in Healthy and Depressive People
}

\author{
Mariola Kokowska (MA) ${ }^{1}$, Maria Dymnikowa $(\mathrm{PhD})^{2 *}$ \\ ${ }^{1}$ music psychologist and music-therapist, SWPS University of Social Sciences and Humanities, \\ Psychology Department, Chodakowska st.19/31, 03815 Warsaw, Poland \\ ${ }_{1,2}^{1,2}$ Laboratory of Music-therapy, Institute of Psychiatry and Neurology, al. Sobieskiego 1/9, 02957 Warsaw, Poland \\ ${ }^{2}$ music psychologist, Association of Musical Psychologists and Psychotherapists, Akademika Anohina st. 38/3, 119602, Moscow \\ ${ }^{2}$ Laboratory of Psychophysiology of Speech, I. P. Pavlov Institute of Physiology of the Russian Academy of Sciences, \\ Makarova nab. 6, 199034 Saint-Petersburg \\ mariolakowska_korab@wp.pldmwl@bk.ru \\ *Corresponding author's email: dmwl@bk.ru
}

\begin{abstract}
The article describes experimental applied music-therapy study about differential characteristics of personality and musical preferences traits for music's regulation properties established empirically in a sample of 92 people, selected by illness, gender and education factors, with psychological musical measurement of TIPI, STOMP and MMR tools, with data of musical factor analysis and psychological analysis of distribution's difference, as pragmatic music-therapy function for human's health.
\end{abstract}

Keywords - Music-therapy in healthy people and with depression, Musical preferences in music-therapy, Music's regulation properties.

\section{INTRODUCTION}

Applied clinical psychology allows using music in the therapeutic process as a useful diagnostic tool for studying psychological processes and applied music-therapy conditions. The interest in psychology in musical preferences is associated with an attempt to get to know some of the mental processes occurring in healthy and sick people when music has a possible relationship with their personality traits or mood changes. Music is a means of mood regulation [35] in the aspect of everyday life by identifying regulation strategies, linking ordinary activities with musical material $[57,58,69]$. It is used in clinical therapy [32, 60], in self-regulation [16, 49,63], to reduce the stress and decrease the tendency to perceive the situation as hopeless [47], and as the influence of art in relation to the experience of depression by people.

According to the definition of the International Statistical Classification of Diseases and Health Problems ICD-10 (International Classification of Disorders), the unipolar affective disorder is a unit classified as recurrent depressive disorder (F.32 and F.33). The diagnosis of subjects is associated with episodes of mild to moderate depression: depressive episode (F.32) and recurrent depressive disorder (F.33). The syndrome of depressive symptoms is related to the mood of prolonged sadness, in which one sees the loss of interests and pleasures, sleep disturbances and appetite, a tendency to guilt and low self-esteem, fatigue and weakened concentration. The causes of the disease are sought among various factors, referring to negative experiences and chronic stress, heredity [34], dysregulation of the circadian rhythm and mechanisms of neurotransmission. Significantly affecting people's ability to function in many areas and their quality of life is subject to various forms of therapy in clinical settings and self-regulation in everyday life. Support for therapy for people with depression in clinical settings is behavioral music-therapy, which interacts with music to restore adaptive behavior. In music-therapy with a receptive approach [23, 24, 26], it's going behind the intentional listening to music in a free or task-oriented manner, which ends the discussion.

In regulatory listening to music, audiovisual media groups are used as methods containing specific content and technical characteristics: visual means (e.g. projectors, graphic and light boards), auditory means (e.g. recording apparatus, phonics) and audiovisual means in the sense of strict (e.g. apparatus for playing sound films and film music, sets for reproducing sound images). The contemporary space of culture (in the aspect of popular music) is a social fact, becoming a source of identification and creation of preferences, lifestyle and the way the recipient experiences the world [30]. Being saturated with the richness and diversity of content and experiences, aroused by the progress of modern electronic media and multimedia - popular culture in the aspect of music is an important element of the everyday life of modern man. 
Therefore, it is worth looking for an area that can be used in music-therapy activities for health, auto-therapy and auditory experience of the recipient world - appearing on the path of the multidimensional process of enriching people with the reception of the content of the audio culture, including musical preferences, also a carrier of extra-visual content. In regulating music listening, which serves adaptive functions [45, 68] and changes in mood, the perspective of illness, personality model [25] and musical preferences appear [52, 53].

\section{APPLIED MUSIC-THERAPY DIAGNOSTIC BACKGROUND}

\subsection{Gosling, Rentfrow and Swan personality traits' model.}

The structural approach to personality (e.g. Allport, Cattel, Eysenck, Big five model of McCare and Costa) formulates a five-factor model, suggesting the universality and biological stage of the factors. The main task of this type of model is to provide a personality profile that allows to predict behavior and not necessarily describe individual uniqueness. In many approaches to the concept of personality, traits are treated as a basic level, i.e. conditioned to a large extent biologically and being in relation with the cohesion of a person's functioning in situations. At the subsequent levels, personality descriptions appear, including adaptations and personal, unique stories of the subject's life [42]. Considering internal factors, i.e. referring to relatively permanent dispositions, in the aspect of music, a psychological model of personality traits is assumed for analysis in a descriptive approach [2, 8 , 13, 19]. The big five model of McCare and Costa [25] is a psychometric trend, where the personality is operationalized in the form of a questionnaire or its abbreviated version. It is an example of a classic division of the personality structure into five factors, a measure describing the subject: neuroticism, extroversion, conscientiousness, agreeableness and openness to experience and. These components are operationalization of factor representation Ten-Item Personality Inventory (TIPI) [25]. A short questionnaire (TIPI-10) for the screening of the disposition is relatively useful in music-therapy.

\subsection{Gosling and Rentfrow music preference model.}

The conditioning of musical preferences with personality traits is known in many studies [5, 41, 45, 51]. The issue of music preferences is associated with the concept of attitude, including the set of processes that shape the individual's awareness and the way it interacts with the social world. In the traditional sense, the attitude contains three components: cognitive (i.e., a relatively persistent belief about the properties of the posture object), affective (i.e. emotional, that is, evaluating the disposition to respond to the attitude object) and behavioral (i.e. actions towards the object of posture) [70]. Individual differences are the basis for the construction of a musical preference model based on processes related to attitude. The term 'musical preferences' is understood as a priority given to a certain type of music and privileged to other people [36], based on the valence level of liking or disliking specific music and musical genres in response to their perception. The recipient's response to their perception does not necessarily have to be strictly based on cognitive analysis and aesthetic reflection but may include a situational context [41]. The looking for separate factors that influence the formation of attitudes towards music is prepared during creating preference models $[12,15,55]$ with the trials of controlling the mood [58].

Individual differences are the basis for the creation and interpretation of the musical preferences model, defined as the internal selection of music and the degree of sympathy for its genre and revealing the tendency to specific behaviors. Exploring the regulation properties of music in terms of preferences for its genres and structural dimensions take place against the background of the social context of everyday life and therapeutic processes in music-therapy. Getting to know the regulatory properties of music in terms of preferences for its genres and structural dimensions take place against the background of the social context of everyday life and therapeutic processes in music-therapy. The process of music standardization (artistic, popular) supports the receptive character of its reception, keeping the listener in a position to search for goals and values in preferences for particular works of musical art - transmitted by audio and audiovisual media (e.g. film music).

The functional role of the musical art (including popular music, artistic music) in music-therapy acquires meaning and value (universal) thanks to its recipients in the sphere of everyday life [22]. Recipients integrate listening to music with many activities (including music), and the process of proper regulation proceeds more effectively when the musical material is selected to the individual needs and preferences of the listener [6]. In the concept of musical preferences [51], music includes factors understood as musical stereotypes, defining musical taste. The stereotype of musical genres' fans is a belief in the categorization in thinking, which is defined as an excessive generalization, simplification or one-sidedness. The categorization of musical genres is based on the preferences of musical listeners, which are correlated, for example, with their personality traits. This conviction is attributed to the listeners of certain musical genres, whose assessment is made in terms of the intensity of the occurrence of certain individual characteristics (characterological, personality, intellectual, physical) or conditioning. 
Classification of musical stereotypes in the perceptual sense defines them as four dimensions:

1. Complex and reflective music (Reflective and Complex) (classical, folk, jazz and blues) - the music of these genres underlines positive and negative emotions, and the compositions are perceived as structurally complex [52]. Their reception promotes introspection. A stereotypical listener of classical music is perceived as educated and older, with a certain level of maturity and financial stability. A listener preferring blues and jazz - is associated with the conviction of a middle-class man using the music played "live". Preferences for classical music are perceived as more attractive and sophisticated for men than women - preferring heavy metal music, perceived as aggressive and rebellious [74].

2. Optimistic and conventional music (Upbeat and Conventional), i.e. film, pop, country, religious has a simple structure and positive message [51]. Proponents of serene music reveal extraversion, agreeableness and a sense of physical attractiveness, although their results negatively correlate with openness to new experiences. There is the conviction that country music is used by neuroscientists who are hungry for conventional music which regulates emotions, and its listeners are considered to be the most stabilized emotionally [37].

3. Intensive and rebellious music (heavy metal, rock, alternative) - emphasizes negative emotions and contains less complex music than other genres [52]. Here comes, among others heavy metal - this is a term generally used, as a collective name for all metal subspecies, as well as a subspecies of metal. Its' characteristic feature are songs in medium and fast tempos, with hard-sounding, aggressive guitar riffs, bass and percussion. Some of the songs are based on a structured pattern: stanza, chorus, verse, chorus, guitar solo, chorus. Topics in heavy metal music are focused around death and dying (death metal), magic, satanic rituals (black metal) and fantasy (power metal). The heavy metal and rock listener is associated with the conviction about their relationship with the art of provocation, i.e. the tendency to problematic behavior [40] as provocative, anti-social, self-destructive, showing internalizing disorders (e.g. mood disorders), independence, anti-conformism and lack of a stable sense of identity [61]. Music contains associations with the stereotype of the listener of genres, in which the need to rebel against society is perceived. People who prefer metal and rock tend to have traits and behaviors that are destructive [21]. Heavy metal fans suffer from depression leading to suicide - posing a threat to themselves and others, although they show great sensitivity and delicacy [28]. Listening to heavy metal calms down, adds active emotions, i.e. motivation and enthusiasm, inspires and gives a subjective sense of power [31], where anger induces motivation [9], and stimulates action, regulates sadness, improves mood and arouses positive emotions [65].

4. Energetic and Rhythmic music (soul, rap / hip-hop, electronic music) emphasizes energy level and self-distribution. These factors describe the characteristics of music that are related to separate patterns (stereotypes) of variables: demographic, personality, cognitive skills $[52,53,54]$.

The Short Test of Music Preferences questionnaire (STOMP-14) [50] was used for musical preferences measurement $[15,75]$.

Regulation of mood is a process that takes place inside the individual human. It involves modulating or sustaining the experienced mood by means of certain behaviors and processes that are under deliberate control or have an automatic aspect [72]. Regulation strategies are a conscious or unconscious orientation of the goal on achieving a certain result of regulation processes [33], which function in literature as a description of possible goals and effects to listening to music $[39,57]$. There are individual differences between people in the preference of the mood regulation strategy: hedonistic (i.e. mood correction) [18] or alternative (i.e. correction and reduction) [57, 66]. Mood regulation combines various mood-determining factors that are external and internal. External factors may include situations and events [38] that improve or worsen the mood [4], and internal - what is essentially related to personality [25, 73]. The concept of music mood regulation [57] assumes that music as an aesthetic stimulus from the environment can participate in the process of changing the mood of the individual - improving it (mood improvement) or controlling it (mood strategies) with the right strategies. They are based on musical activities that involve: listening to music, playing an instrument, singing and writing songs, movement and dancing. Musical strategies are expressed in 6 dimensions: entertainment, renewal, strong sensation, diversion, discharge, overwork (mental work). Strategies are measured using the Music in Mood Regulation (B-MMR) questionnaire [59]. The Polish adaptation of MMR - Music in Mood Control by Gugnowska [27] was used in music-therapy study. 


\section{APPLIED EXPERIMENTAL MUSIC-THERAPY STUDY DESCRIPTION}

The experimental study music-therapy study concerned of differences between healthy persons and with depression in the frame of musical preferences' structure, with empirical verification by analysis of distribution's difference in empirical samples and factor analysis (with main components' method and normalized Equamax rotation). The assessment concerned personality traits [51], musical preferences [25] and mood regulation by music [57]. The study was completed during music-therapy scientific stage in the laboratory of music-therapy in Institute of Psychiatry and Neurology in Warsaw (Poland) under supervision of national music-therapist dr E. Galinska, on the basis of Master clinical psychology specialization (M. Kokowska) and Post-graduate specializations in practical psychological diagnosis and clinical neuropsychology with practical approach (M. Dymnikowa) with scientific experience in fixing the structure of healing music [17].

The purpose of the study was to determine the structure of music preferences and to find the differences in the intensity of personality traits and musical preferences in terms of applying the mood regulation strategies by music in healthy people and with depression, with including the gender and education factors. Dependent variables determined the strategies of mood regulation with music (detachment, overworking of feelings, strong experiences, unloading, regeneration / animation, entertainment). Independent variables determined: 1. Music preferences for music genres - complex and reflective, optimistic and conventional, intense and rebellious, energetic and rhythmic. 2. Personality traits (neuroticism, extraversion, conscientiousness, agreeableness and openness to experience). Controlled variables determined the diagnosis of disease (F.32 and F.33), sex, age and education. The classification of patients included episodes of mild to moderate depression: i.e. depressive episode (F.32) and recurrent depressive disorder (F.33). People assigned to the depression group were qualified by a medical diagnosis of unipolar depression, according to the criterion of unipolar depression according to ICD-10 classification (i.e. International Classification of Disorders).

The study was conducted on an empirical sample (statistical age data od mean and standard deviation values) of 50 people with depression (age data: $\mathrm{M}=48.24, \mathrm{SD}=9.51$ ) and 42 healthy people (age data: $\mathrm{M}=40.97$, $\mathrm{SD}=12.60$ ). A total of 52 women (age data: $\mathrm{M}=44.25, \mathrm{SD}=12.07$ ) and 40 men (age data: $\mathrm{SD}=45.80, \mathrm{SD}=10.92$ ) participated in the study, from which two equal subgroups with 46 people with middle education (age data: $\mathrm{M}=44.28, \mathrm{SD}=10.04$ ) and higher education (age data: $\mathrm{M}=45.56, \mathrm{SD}=12.97$ ) were formed up. The comparative analysis of healthy people and with depression, also with gender groups included non-parametric statistics (Mann-Whitney test), while parametric statistics (Student test) were applied for two equal educational groups. The music-therapy research with voluntary participation lasted about 30 minutes, from filling out three questionnaires TIPI, MMR, and STOMP with the realization of listening to music and current attitude to presented incentives, by using the Likert scale of estimation (from 'I strongly disagree' till 'I strongly agree').

STOMP (Short Test of Music Preferences STOMP-14) is the music questionnaire used for musical preferences' measurement $[15,75,51]$. It describes the intensity of preferences for the favorite dimension of music or its genres from among 14 musical examples. TIPI (Ten-Item Personality Inventory) is the short psychological version of the big-five model personality questionnaire (Rentfrow, Gosling and Swann, 2003) with 10 statements. MMR (Music Mood Regulation) is the music questionnaire used to measure mood regulation strategies with the use of music in everyday life [57] with 34 statements. The structure of the questionnaire is based on dimensions defining musical strategies: 1. Detachment (discharge) - the task of music is to divert attention from unpleasant thoughts and cut off from negative emotions (anger, sadness, depression). 2. Overwork (mental work) - it's lonely listening and writing songs; music as a background favors reflection and contemplation, transferring the listener to the past; helps to gain insight, re-evaluate and accept personal content. 3. Strong Experiences (strong sensation) - music is to intensify the emotional experience. 4. Redirection, discharge (diversion) - music releases emotions (anger, sadness, depressiveness), and synchronizing with the mood brings a momentary cleansing (catharsis). 5. Renewals, regeneration (Revival) - listening to music and singing as well as playing and writing songs, providing regeneration and relaxation, and regaining life energy. 6. Entrainment - a strategy where music as a background provides stimulation and creates a positive mood. 


\section{APPLIED MUSIC-THERAPY STUDY DATA REPORT}

\subsection{STOMP and MMR factor analysis.}

The explanation of variance at $63 \%$ for STOMP and $65 \%$ for MMR was obtained during the factor analysis for STOMP and MMR normalized scales on the entire test sample $(\mathrm{N}=92)$ with the principal component method for the separation of factors with normalized Equamax rotation. It confirms that both questionnaires measuring musical preferences are equally reliable in terms of measurement, including the subjective factor of music preference of a musical and aesthetic basis.

An arrangement of 2 factors with 1 negative charge was obtained for the MMR with the following values: I. First factor's value 2,98 with factor components' loads: entertainment +0.78 ; detachment +0.79 ; regeneration +0.79 ; strong survival +0.63 ; overcoming feelings +0.78 . The first factor is the thematic approach to prevention and ready music stimulation (not own therapeutic activity through music) as directions of emotional experiences and emotional uses through music with treating music as a stimulation ready for different activities, directions. II. Second factor's value 1,17 with factor components' loads: discharge 0.85, strong experiences -0.6. The second factor is the thematic approach to active music therapy, where music is a means of expressing the negative emotions of the listener and the source of own therapeutic music-making as a means of emotional expression. Negative loading of the scale of strong experiences, in which it is about seeking intense emotional sensations achieved by music, is the opposite to the human condition, full of emotional sensations and expressing and unloading these emotions through practical music therapy or self-expression through music, understood as a therapeutic expression. The present results of the MMR questionnaire structure are in line with previous empirical studies by S. Saarikallio [56] on a total sample of 1515 subjects.

An arrangement of 5 factors with all positive charges was obtained for the STOMP with the following values: I. First factor's value 2,73 with factor components' loads of STOMP numeral pieces: I with 0.69 , II with 0.79 , III with $0.6, \mathrm{~V}$ with $0.68, \mathrm{X}$ with 0.46 . It is a thematic view of melodically enriched species with the following components: classical, blues, country, folk, jazz.

II. Second factor's value 2,45 with factor components' loads of STOMP numeral pieces: IV with 0.68, VI with 0.68 , VII with 0.61 , XII with 0.56 . It is a thematic view of dance genres - movement with the following components: dance, electronica, rap, hip-hop, funk.

III. Third factor's value 1,27 with factor components' loads of STOMP numeral pieces: XI with 0.8, XIII with 0.56. It is a thematic approach to rhythmically enriched species with the following components: rock, heavy metal. IV. Fourth factor's value 1,08 with factor components' loads of STOMP numeral pieces: VIII with 0.64 , IX with 0.84 . It is a thematic reflection of reflective species (with saturated deep personal reflection) with the following components: religious, alternative.

The mentioned above four structural components of musical categories fully coincide with the results of Rentfrow and Gosling [51] previous empirical studies, obtaining the following classification: 1. complex and reflective music (classical, jazz, blues, folk). 2. energy and rhythmic music (rap, hip-hop, soul / funk, electronic and dance music dance, disco). 3. intense and rebellious music (rock, heavy metal, alternative music). 4. sunny and conventional music (country, pop, religious music, film soundtracks).

V. Fifth factor's value 1,21 with factor component load of STOMP numeral piece XIV with 0.76 is a thematic approach to the theme songs (soundtracks) as a genre in which the word is key or more significant than the background music. It is a characteristic element that extends the diagnostic properties of the STOMP tool.

\subsection{Comparative analysis of healthy people and people with depression.}

Analysis of the age category revealed statistically significantly higher age ratings in the group of people with depression [1] than in the healthy group [2]: $M_{1}=48.24 ; M_{2}=40.97 ; \Sigma_{R A N K S I}=2719 ; \Sigma_{R A N K S 2}=1559 ; U=656 ;$ $Z=3,086 ; D_{C O H E N}=0.68$ (i.e. medium difference); $\left.p<0.01\right]$. Thus, the empirical test of people with depression is older compared to the empirical control sample of healthy people. Analysis of scales' distribution showed significant statistical differences between the groups of people with depression and healthy people in the Mann-Whitney U test for the following variables: the characteristics of unloading and overworking feelings in the MMR questionnaire, extraversion feature in the TIPI questionnaire.

Healthy people showed higher rates than people with depression for the following two features:

1. Unloading (redirecting feelings), measured by MMR questionnaire [point scale: $M_{1}=10.74 ; M_{2}=13.66$; $\Sigma_{R A N K S 1}=1976 ; \Sigma_{\text {RANKS } 2}=2302 ; U=701 ; Z=2,74 ; D_{\text {COHEN }}=0.595$ (i.e. medium difference); $p<0.01 ;$ sten scale: $M_{1}=4.58 ; M_{2}=5.61 ; \Sigma_{\text {RANKS1 }}=1957.5 ; \Sigma_{R A N K S 2}=2320.5 ; U=682,5 ; Z=2,926 ; D_{\text {COHEN }}=0.63$ (i.e. medium difference); $p<0.01$; normalized scale: $M_{1}=1.92 ; M_{2}=2.23 ; \Sigma_{R A N K S I}=1668 ; \Sigma_{R A N K S 2}=2610 ; U=765$; $Z=2,353 ; D_{C O H E N}=0.479$ (i.e. small difference); $p=0.01$ ]. 
2. Extraversion measured by TIPI questionnaire [point scale: $M_{I}=7.56 ; M_{2}=9.52 ; \Sigma_{R A N K S I}=1949 ; \Sigma_{\text {RANKS2 }}=2329$; $U=674 ; Z=2,959 ; D_{\text {СОнеN }}=0.646$ (i.e. medium difference); $p<0.01$ ].

These features are related to depression syndromes and might be the characteristic personality indicators for the predisposition of the disease's incidence. Depression is characterized by a tendency to the introvert, self-closeness, and difficulties in the discharge of emotional tensions, including emotional ones, and the regeneration of emotions in overcoming current difficulties in everyday activities. The conditions of this research may also have a background in the obtained results because the empirical group with people with depression was older than in the control group with healthy people. Older people have a greater tendency to fall into their fate, their world and are more introverted with age. They also tend to remember their biographical fate and difficulties with experiencing these memories with elements of positive and behavioral rejection of negative emotions associated with biographical memories of the past. The strategy of mood regulation 'redirection' i.e. discharge (diversion), being the expression of the release of negative emotions with the help of pleasant music and synchronizing with the current mood by forgetting unwanted thoughts and feelings, brings temporary relief. Research indicates that by modifying negative emotions using positive music, listeners cope with short-term stress at an early stage and with negative emotions, which is cognitive reinterpretation of emotional experiences: by redirecting attention to a pleasant emotional musical stimulus - which is not necessarily a desirable strategy in the state advanced depression [59].

Additionally healthy people showed lower rates than people with the depression group for the characteristics of overworking feelings, measured by MMR questionnaire: [point scale: $M_{1}=21.32 ; M_{2}=19.16 ; \Sigma_{R A N K S I}=2586$; $\Sigma_{R A N K S 2}=1692 ; U=789 ; Z=2,046 ; D_{C O H E N}=0.437$ (i.e. small difference); $p=0.04$; normalized scale: $M_{I}=2.14$; $M_{2}=1.92 ; \Sigma_{R A N K S I}=2082 ; \Sigma_{R A N K S 2}=2196 ; U=807 ; Z=2,036 ; D_{\text {COHEN }}=0.405$ (i.e. small difference); $p=0.04$ ].

This result might be a proof of the important characteristics of people with depression who are aware of their illness and more deliberately try to work on their emotional state, including the process of feeling analysis, reevaluation, overworking and self-understanding. Healthy persons who are not affected by such a disease are deprived of random and living necessity in developing this cognitive-emotional trait. Considering the advantage of older people in the empirical test of depression, the result may also be a characteristic of the elderly, in which distances to the current situation and the advantage of common sense over emotional experiencing and perception of reality, which determines lower demand for more cognitive awareness overworking feelings and saturation with their cognitive, objective and common sense factors.

Analysis of scales' distribution revealed significant statistical differences in mean values of the Mann-Whitney U test for varying preferences of country and pop music in the STOMP questionnaire between groups of healthy people and with depression. Healthy people obtained higher preference indices for country music than people with depression:[normalized scale: $M_{1}=2.16 ; M_{2}=2.45 ; \Sigma_{R A N K S I}=2045.5$; $\Sigma_{R A N K S 2}=2232.5 ; U=770.5 ; Z=2,419 ; D_{\text {COHEN }}=0.469$ (i.e. small difference) $; p=0.01$ ].

Optimistic and conventional music (film, pop, country, religious) - has a simple structure and positive message [51]. Proponents of serene music reveal extraversion, agreeableness and a sense of physical attractiveness, although their results negatively correlate with openness to new experiences. There is the conviction that country music is used by neuroscientists who are hungry for conventional music - which regulates emotions, and its listeners are considered to be the most stabilized emotionally [37]. Healthy people with high scores conciliatory features prefer listening to music: energy and rhythm. Research suggests that preferring popular music styles correlates with kindness, which is a component of conciliation [51]. Preferring energetic and rhythmic music (i.e. soul, rap / hip-hop, electronic), people with a tendency to conciliation - try to accentuate the energy level and bring about self-identification in reception [52, 53]. Healthy men with a low tendency to use music as a mood regulation strategy on the 'entertainment scale' - allowing to maintain a positive mood, prefer listening to thematic songs (soundtrack). They are belonging to the category of film music and contain in their structure the dominance of the text, a concrete leitmotif - to build tension in the development of the narrative. They are the main carrier of non-visual content present in the film. The category of optimistic and conventional music contains, in its structure, theme songs, presenting a simple structure and positive message [51]. Research shows, that the choice of optimistic and fast music treated as a strategy favors the activation, stimulation and growth of the listener's energy. Study on healthy populations suggests that listening to music that reflects a negative mood is essentially a healthy activity and serves as a means of gaining relief and relief [57], distraction and reassessment [67].

Healthy people obtained lower preference indices for pop music than people with depression: [normalized scale: $M_{I}=2 ; M_{2}=1.69 ; \Sigma_{\text {RANKSI }}=2578.5 ; \Sigma_{\text {RANKS } 2}=1699.5 ; U=796.5 ; Z=2,176 ; D_{\text {COHEN }}=0.424$ (i.e. small difference); $p=0.02$ ]. This result has symptom of independent Rentfrow and Gosling [51] studies, which revealed that optimistic and conventional music, the component of which is pop style (country, religious, soundtrack): 1. Positively correlates with extraversion, agreeableness and conscientiousness, as well as conservatism and attractiveness and physical fitness; 
2. Negatively correlates with openness to new experiences, liberalism and verbal skills. Studies of a healthy population regarding the popularity of music genres revealed that the most chosen musical style is pop, and the least popular - classical music, heavy metal and hard-house. Differences based on gender groups, level of education and age show that women are more positive towards pop music, and dance styles belong to the preferences shown by men [46]. These research show that young people who prefer pop music in the context of considering the evolution of popular music - are struggling with the problem of excessive responsibility and balance between dependence and autonomy, sexuality, mutual acceptance [61]. It can be assumed that the popularity and preferences for pop music are related to its structural structure, which contains simple melodies and is predictable in terms of rhythm, text and dance. The theme of these songs reflects references to the recipient's development processes, which concerns issues related to relations, identity and acceptance. In addition, pop music is more correlated with extraversion than heavy metal [3], and when it is played as unromantic male flower florists spend less money on it [29].

\subsection{Comparative analysis of men and women.}

Analysis of scales' distribution showed a statistically significant difference in the mean values between groups of women (1) and men (2) for neuroticism measured by TIPI questionnaire, with higher results in men than in women [point scale: $M_{1}=6.15 ; M_{2}=7.57 ; \Sigma_{\text {RANKSI }}=2092 ; \Sigma_{\text {RANKS2 }}=2186 ; U=714 ; Z=2,587 ; D_{\text {COHEN }}=0.556$ (i.e. medium difference); $p<0.01]$.This data is consistent with previous studies that confirmed sexual conditioning in the development of neuroticism. Neuroticism (emotional instability) is a trait that marks a lasting tendency to experience negative emotions. It is not a disorder or disease, but a characteristic describing personality, being treated as a risk factor for anxiety and mood disorders [43]. People who achieve high rates of neuroticism are more exposed to negative responses to stressors and more quickly identify difficult situations as hopeless [47]. Negative emotions in comparison to high neuroticism diminish satisfaction with the present and anticipate future events, while low neuroticism is combined with a higher quality of life [62].

The studies show sex differences in the neuroticism of men and women, occurring in different cultures [14], being able to be of importance in older age [64]. The result of the current music-therapy research refers to studies [14], in which the comparative analysis of differences in personality traits from the big five model canon established that the differences between the sexes are small but slightly larger in the case of neuroticism. Women get a higher tendency to anxiety, depression and angry hostility, but give way to higher men's results in impulsiveness, which is a component of neuroticism [71]. In the context of music, analyzes show that anxiety and neuroticism are higher in recipients listening to sad or aggressive music, which is a way of expressing negative feelings - especially by men, which does not necessarily improve the negative mood and is a positive strategy. Neuroticism is positively correlated with the use of music for emotional regulation and experiencing a higher intensity of negative emotions [7, 44].

Present empirical data also confirm that depression is not a decisive factor in the level of neuroticism in humans, therefore neuroticism may not be an important clinical indicator for estimating the probability and inclination of people in this disease. Considering the older age of the empirical trial with depression, the result also shows that neuroticism is not a feature specific to older people and is not significantly developed with age. The studies of Abeles [1], Christenson and Peterson [10], Christenson and Roberts [11], Finnas [20], Rawlings and Cianciarelli [50], revealed significant gender determinants of the specificity of music preferences, where men are more likely to choose heavy and hard music with aggressive elements (such as rock and roll, progressive rock, heavy rock, heavy metal), while women choose dance, disco, pop and folk music. These results suggest a higher level of irritability presented in men with the state of increased aggressive tension (due to the preference for aggressive music), which may translate in the personality structure to an elevated level of neuroticism and requires verification in further empirical studies.

\subsection{Comparative analysis of people with middle and high education.}

Analysis of distribution of normalized MMR scales - the scale of searching for intense emotional experiences through music and the scale of reevaluating the events and feelings through music - revealed significant statistical differences in mean values between groups of people with middle (1) and higher (2) education in the Student's t-test. People with higher education have shown statistically significantly different tendency in comparison to people with middle education:

1. Higher indicators of searching for intense emotional experiences through music [normalized scale: $M_{I}=1.89$; $S D_{1}=0.76 ; M_{2}=2.21 ; S D_{2}=0.72 ; t_{90}=2 ; D_{\text {COHEN }}=0.432$ (i.e. small difference) $; p=0.03$ ];

2. Higher scores for the STOMP music category „Intensive and rebellious "(components of music genres: Rock, Alternative Rock, Heavy Metal) [point scale: $M_{1}=13.91 ; S D_{1}=4.61 ; M_{2}=16.67 ; S D_{2}=3.34 ; t_{90}=3.28$; $D_{\text {COHEN }}=0.686$ (i.e. medium difference); $\left.p<0.01\right]$, and for the agreeableness' feature in TIPI questionnaire [point scale: $M_{1}=8.36 ; S D_{1}=3.22 ; M_{2}=9.97 ; S D_{2}=3.58 ; t_{90}=2.26 ; D_{\text {COHЕN }}=0.473$ (i.e. small difference); $p=0.02$ ]. 
3. Lower indicators of reevaluating events and feelings through music [point scale: $M_{1}=21.34 ; S D_{1}=4.81 ; M_{2}=19.32$; $S D_{2}=4.86 ; t_{90}=2 ; D_{C O H E N}=0.418$ (i.e. small difference); $p=0.04 ;$ sten scale: $M_{1}=6.08 ; S D_{l}=1.83 ; M_{2}=5.32 ;$ $S D_{2}=1.62 ; t_{90}=2.1 ; D_{\text {COHEN }}=0.44$ (i.e. small difference) $; p=0.03$ ].

People with higher education show higher preferences (higher level of favorite) of genre intensive and rebellious music (genres Rock, Alternative Rock, Heavy Metal) in comparison to people with middle education. This preferential tendency might be result from the conditions, style of work and lifestyle of people with higher education, which show a greater tendency for work-dependence, shaping their professional career and professional development. It requires a lot of struggles in a short time and conditions the lifestyle at a very "high speed" causing tension. Such people are prone to greater fatigue and higher demand for energizing music, mobilizing to struggles and responsibilities related to higher education, which largely satisfy the music genres of the "intense and rebellious" category and allow a higher level of energy arousal through frequent listening to this music, and thus cause relief and energy facilitation in the performance of work and activities related to the specificity of higher education. People with higher education show a higher tendency towards agreeableness in comparison to people with middle education, which might have a background in the level of development and cognitive maturity of a human being acquired as a result of higher education as a process of shaping and developing a person's personality. People with higher education also have slightly lower preferences in using music to rethink their problems, to re-evaluate and accept events that cause difficult emotions, experiences and moments. This may be due to a higher preference for intense rebellious music, which carries energy potential and gives people energy, which in turn may facilitate their easier and less painful entry into their troubles, difficulties and more effective solution. Such music also helps to enter into a state of emotions isolated from the current real situation and to immerse people in their internal world and personal conditions, thus finding more optimal strategies for dealing with current negative emotions, experiences and events.

Analysis of distribution of normalized STOMP scales - of music preferences styles such as country, alternative rock and heavy metal - revealed significant statistical differences in mean values between groups of people with middle (1) and higher (2) education in the Student's t-test. People with higher education have shown statistically significantly different tendency in comparison to people with middle education:

1. Higher indicators of country music preferences $\left[M_{1}=2.13 ; S D_{1}=0.65 ; M_{2}=2.45 ; S D_{2}=0.62 ; t_{90}=2.45\right.$; $D_{\text {COHEN }}=0.504$ (i.e. medium difference); $p=0.01$ ];

2. Lower indicators of alternative rock music preferences $\left[M_{1}=2.67 ; S D_{1}=0.51 ; M_{2}=2.32 ; S D_{2}=0.76 ; t_{90}=2.55 ;\right.$ $D_{\text {COHEN }}=0.541$ (i.e. medium difference); $\left.p=0.01\right]$; and heavy metal music preferences $\left[M_{l}=2.76 ; S D_{l}=0.56 ;\right.$ $M_{2}=2.41 ; S D_{2}=0.74 ; t_{90}=2.5 ; D_{C O H E N}=0.533$ (i.e. medium difference) $\left.; p=0.01\right]$.

For empirical partial subgroups' qualitative analysis:

1. People with higher education and with a low tendency to seek intensive emotional experiences through music do prefer listening to classical music.

2. Healthy people with a low tendency to seek intensive emotional experiences through music additionally do prefer listening to jazz and blues music, of a reflexive and complex nature.

3. Men with higher education and with low tendency to relieve grief and anger through music do prefer listening to electronic, rap, hip-hop and funk music, of an energetic and rhythmic character. They should be included in music-therapy service for human's emotional regulation.

\section{CONCLUSION}

The article attempted to capture differences in the structure of musical preferences, personality traits and the use of music mood regulation strategies in depressed and healthy people. Empirical results confirm, that in accordance per the adopted assumptions, there were differences in the groups in terms of the analyzed indicators. The following conclusions, presented below, can be tentatively proposed from realized research.

1. Healthy people, in comparison to patients with depression, differ in terms of the tendency to discharge negative emotions and overwork feelings and personal life events, showing a moderately higher tendency to unload negative emotions and lower to overwork feelings - regulating the mood with music. Being healthy, they are moderately less likely to show extraversion tendencies.

2. Healthy people, compared to people with depression, show moderately higher readiness to prefer country and pop music. Healthy people with a tendency to high agreeability, prefer listening to music: electronic, energy and rhythmic. Healthy men, with a low tendency to use music as an entertainment strategy to maintain a positive mood prefer to listen to themed songs (soundtrack). Healthy people also show moderately lower readiness to prefer pop music in comparison to people with depression.

3. Men have been shown to have a moderately higher tendency towards neuroticism compared to women. 
4. People with higher education show, compared to people with secondary education, a moderately higher tendency to regulate the mood by listening to music, looking for intense emotional experiences in it - which allows them probably to obtain a higher level of arousal and brings a voltage discharge. They also have a moderately greater tendency to listen as a favorite (popular) - i.e. intense and rebellious music, whose components are: rock, alternative rock, heavy metal, when they exhibit the features of agreeableness. Also people with higher education show a lower tendency to regulate the mood with music when its impact is about the reevaluation of feelings and a moderately higher tendency towards agreeableness, in comparison to people with secondary education.

Totally the regulatory properties of music are an issue undertaken by music psychology in the aspect of personality traits, musical preferences and mood. It requires more scientific attention in the prism of the attributes of music (classical, popular) - used in common behaviors of everyday life in the prevention and clinical interactions of music therapy, it requires more replicable scientific studies. The direction of cognition and empirical verification, yielding benefits or their unfavorable influence to the contexts of regulatory impacts of music - should take into account the complexity resulting from individual differences. Searching for regulatory attributes, potentially included in the context of musical art, becomes the art of thinking with sounds [48] and feeling oneself and the surrounding world through sounds. It contains properties exhibited by persons in a state of health and illness, which should be subjected to further research procedures in the context of the application of audio or audiovisual media resources for communication.

\section{REFERENCES}

[1] Abeles, H. F. (1980). Responses to music. In D. A. Hodges (Ed.), Handbook of music psychology. Lawrence, KS: National Association for Music Therapy. P.105-140.

[2] Allport, G. W. (1937). Personality: a psychological interpretation. New York: Holt, Rinehart and Winston.

[3] Baker, F., Bor, W. (2008). Can music preference indicate mental health status in young people. Australian psychiatry, $16(4)$, p.284-288.

[4] Biernacki, M. P., Jankowski, K. S., Kowalczuk, K., Lewkowicz, R., Dereń, M. (2012). +Gz centrifugation and mood. Aviation, space and environmental medicine, February, 83 (2), p.136-139.

[5] Brown, R. A. (2012). Music preferences and personality among Japanese University students. International journal of psychology, 47, p.259-268.

[6] Buhn, H. (2002). Musical Development of elderly people. Psychomusicology, 18 (1-2), p.59-75.

[7] Carlson, E., Saarikallio, S., Toiviainen, P., Bogert, B., Kliuchko, M., Brattico, M. (2015). Maladaptive and adaptive emotion regulation through music: a behavioral and neuroimaging study of males and females. Frontiers in human neuroscience, August, 9, art. 466.

[8] Cattell, R. B. (1959). Personality theory growing from multivariate quantitative research. In S. Koch (Ed.), Psychology: a study of a science (p.257-327). New York: McGraw-Hill.

[9] Chen, F. F. (2007). Sensitivity of goodness of fit indexes to lack of measurement invariance. Structural equation modeling, 14, p.464-504.

[10] Christenson, P. G., Peterson, J. B. (1988). Genre and gender in the structure of music preferences. Communication research, 15, p.282-301.

[11] Christenson, P. G., Roberts, D. F. (1998). It's not only rock and roll: popular music in the lives of adolescents. Cresskill, NJ: Hampton Press, Inc.

[12] Collingwood, J. (2008). Preferred music style is tied to personality. Psych central. Retrieved on October 10, 2018, https://psychcentral.com/lib/preferred-music-style-is-tied-to-personality/

[13] Costa, P. T. Jr., McCrae, R. R. (1992). Revised NEO personality inventory (NEO-PI-R) and NEO five-factor inventory (NEO-FFI) professional manual. Odessa, FL: Psychological Assessment Resources.

[14] Costa, P. T., Terracciano, A., McCrae, R. R. (2001). Gender differences in personality traits across cultures robust and surprising findings. Journal of personality and social psychology, 81 (2), p.322-331.

[15] Delsing, M. J. M. H., ter Bogt, T. F. M., Engels, R. C. M. E., Meeus, W. H. J. (2007). Adolescents' music preferences and personality characteristics. European journal of personality, 22, p.109-130.

[16] DeNora, T. (2001). Aesthetic agency and musical practice: new directions in the sociology of music and emotion. In P. N. Juslin, J. A. Sloboda (Ed.), Music and emotion: theory and research (p.161-180). New York: Oxford University Press.

[17] Dymnikowa, M. (2016). Physiological aspects of music and longevity. Advances in gerontology, April, 6 (2), p.101-110.

[18] Erber, R., Erber, M. W. (2000). The Self-Regulation of Moods: second thoughts on the importance of happiness in everyday life. Psychological inquiry, 11, p.142-148.

[19] Eysenck, H. J. (1952). The scientific study of personality. London, United Kingdom: Routledge and Kegan Paul.

[20] Finnas, L. (1989). How can musical preferences be modified? A research review. Bulletin of the council for research in music education, 102, p.1-58.

[21] Fried, C. B. (2003). Stereotypes of music fans: are rap and heavy metal fans a danger to themselves or others? Journal of media psychology, 8 (3), p.1-27. 
[22] Frith, S. (1983). Sound effects: youth, leisure and the politics of rock and roll. Constable, London.

[23] Galińska, E. (2005). Muzykoterapia. In L. Grzesiuk [Ed.], Psychoterapia. Teoria. Podręcznik akademicki. nr 1, p.531-542. Warszawa, Poland: Instytut Psychologii Uniwersytetu Warszawskiego. Eneteia.

[24] Galińska, E. (2008). Rola struktur i form muzycznych w psychoterapii. Muzyka, 3, p.47-77.

[25] Gosling, S. D., Rentfrow, P. J. i Swann, W. B. (2003). A very brief measure of the Big-Five personality domains. Journal of research in personality, 37, p.504-528.

[26] Grocke, D., Wigram, T. (2007). Receptive methods in music therapy: techniques and clinical applications for music therapy clinicians, educators and students. London and Philadelphia: Jessica Kingsley, p.1-271.

[27] Gugnowska, K. (2015). Muzyka w regulacji nastroju. MA thesis, Psychology department of Warsaw University, Poland.

[28] Hargreaves, D.J., North, A.C., Tarrant, M. (2006). Musical preference and taste in childhood and adolescence. In G. E. McPherson (Ed.), The child as musician, p.135-154, Oxford: Oxford University Press.

[29] Jacob, C., Guéguen, N., Boulbry, G., Sami, S. (2009). Love is in the air: congruence between background music and goods in a florist. The international review of retail, distribution and consumer research, p.75-79.

[30] Jakubowski, W., Zierkiewicz, E. (2002). Edukacyjne konteksty kultury popularnej, Kraków, Poland: Impuls.

[31] Juslin, P. N., Liljeström, S., Västfjäll, D., Barradas, G., Silva, A. (2008). An experience sampling study of emotional reactions to music: listener, music, and situation. Emotion, October, 8 (5), p.668-683.

[32] Juslin, P. N., Västfjäll, D. (2008). Emotional responses to music: the need to consider underlying mechanisms. Behavioral and brain sciences, 31, p.559-621.

[33] Kalolly, F. (1993). Mechanisms of self-regulation: a system view. Annual review of psychology, 44, p.23-52.

[34] Kessler, R. C., Berglund, P., Demler, O., Jin, R. (2003). The epidemiology of major depressive disorder: results from the National Comorbidity Survey Replication (NCS-R). JAMA, June, 289 (23), p.3095-3105.

[35] Kokowska, M. (2017). Doświadczenie muzyczne w regulacji nastroju. Polskie forum psychologiczne, 22 (91), p.57-81.

[36] Kopaliński, W. (1990). Słownik wyrazów obcych $i$ zwrotów obcojęzycznych. Warszawa, Poland: Wiedza powszechna.

[37] Langemyer, A., Guglhör-Rudan, A. I Tarnai, C. (2012). What do music preferences reveal about personality? A cross-cultural replication using self-ratings of music samples. Journal of individual differences, 33, p.119-130.

[38] Lawrence, C. (2006). Measuring individual responses to aggression-triggering events: Development of the situational triggers of aggressive responses (STAR) scale. Journal of aggressive behavior, 32, p.241-252.

[39] Laukka, P. (2007). Uses of music and psychological well-being among the elderly. Journal of happiness studies, 8 , p.215-241.

[40] Lester, D., Whipple, M. (1996). Music preference, depression, suicidal preoccupation, and personality: comment on stack and gundlach's papers. Suicide and life-threatening behavior, 26 (1), p.68-70.

[41] Lewandowski, R. (2011). Osobowościowe uwarunkowania preferencji muzycznych w zależności od wieku. Kraków, Poland: Impuls.

[42] McAdams, D. P. (1995). What do we know when we know a person? Journal of personality, 63, p.365-396.

[43] Matthews, G., Deary, I. J. (1998). Personality traits. Cambridge, United Kingdom: Cambridge University Press.

[44] McFerran, K., Saarikallio, S. (2014). Depending on music to make me feel better: who is responsible for the ways young people appropriate music for health benefits. The arts in psychotherapy, 41, p.89-97.

[45] Miranda, D., Claes, M. (2008). Personality traits, music preferences and depression in adolescence. International journal of adolescence and youth, 14, p.277-298.

[46] Mulder, J. (2008). Use it or lose it: music preferences and uses related to psychosocial functioning among adolescences and young adults. $\mathrm{PhD}$ thesis, Utrecht University. Wageningen: Ponsen and Looijen.

[47] Nevid, J. S., Rathus, S. A. (2007). Psychology and the challenges of life: adjustment in the new millennium. New York: Wiley.

[48] Ossowski, S. (1966). U podstaw estetyki. Warszawa, Poland: PWN.

[49] Pelletier, C. L. (2004). The effect of music on decreasing arousal due to stress: a meta-analysis. Journal of music therapy, 16 (3), p.192-214.

[50] Rawlings, D., Cianciarelli, M. (1997). Music preference and the five-factor model of the NEO personality inventory. Psychology of music, 25, p.120-132.

[51] Rentfrow, P., Gosling, S. (2003). The do re mi's of everyday life: the structure and personality correlates of music preferences. Journal of personality and social psychology, 84 (6), p.1236-1256.

[52] Rentfrow, P. J., Gosling, S. D. (2006). Message in a ballad: the role of music preferences in interpersonal perception. Psychological science, 17, p.236-242.

[53] Rentfrow, P. J., Gosling, S. D. (2007). The content and validity of music-genre stereotypes among college students. Psychology of music, 35, p.306-326.

[54] Rentfrow, P. J., McDonald, J. A., Oldmeadow, J. A. (2009). You are what you listen to: young people's stereotypes about music fans. Group processes and intergroup relations, 12, p.329-344. 
[55] Rentfrow, P. J., Goldberg, L. R., Levitin D. J. (2012). The structure of musical preferences: a five-factor model. Journal of personality and social psychology, June, 100 (6), p.1139-1157.

[56] Saarikallio, S. (2006). Differences in adolescents' use of music in mood regulation. Proceedings of the $9^{\text {th }}$ International Conference on Music Perception and Cognition (ICMPC), Bologna, Italy, August 22-26, p.953-959.

[57] Saarikallio, S., Erkkilä, J. (2007). The role of music in adolescents' mood regulation. Psychology of music, 35, p.88-109.

[58] Saarikallio, S. (2008). Music in mood regulation: initial scale development. Musicae scientiae, 12, p.291-309.

[59] Saarikallio, S. (2012). Development and validation of the brief music in mood regulation scale (B-MMR). Music perception: an interdisciplinary journal, 30 (1), p.97- 105.

[60] Särkämö, T., Tervaniemi, M., Laitinen, S., Forsblom, A., Soinila, S., Mikkonen, M., Autti, T., Silvennoinen, H. M., Erkkila, J., Laine, M., Peretz, I., Hietanen, M. (2008). Music listening enhances cognitive recovery and mood after middle cerebral artery stroke. Brain: a journal of neurology, March, 131 (3), p.866-876.

[61] Schwartz, K. D., Fouts, G. T (2003). Music preferences, personality style, and developmental issues of adolescents. Journal of youth and adolescence, 32 (3), p.205-213.

[62] Siwy-Hudowska, A. (2013). Quality of life and personality of young men with varying degrees of involvement in physical excercises. Studia psychologiczne, 52 (3), p.63-72.

[63] Sloboda, J. A., O’Neill, S. A. (2001). Emotions in everyday listening to music. In P. N. Juslin, J. A. Sloboda (Ed.), Music and emotion: theory and research. p.71-104. New York: Oxford University Press.

[64] Smith, T. W., Spiro, A. (2002). Personality, health, and aging: prolegomenon for the next generation. Journal of research in personality, August, 36 (4), p.363-394.

[65] Thoma, M. V., La Marca, R., Brönnimann, R., Finkel, L., Ehlert, U., Nater, U. M. (2013). The effect of music on the human stress response. PLoS ONE, 8(8), art. e70156.

[66] Tice, D. M., Braslavsky, E. (2000). Giving to feel good: the place of emotion regulation in the context of general self-control. Psychological inquiry, 11, p.149-159.

[67] Van den Tol, Annemieke, J. M., Edwards, J. (2013). Exploring a rationale for choosing to listen to sad music when feeling sad. Psychology of music, 41 (4), p.440-465.

[68] Trehub, S. E. (2003). Musical predispositions in infancy: an update. In I. Peretz, R. Zatorre (Ed.), The cognitive neuroscience of music. p.3-20. New York: Oxford University Press.

[69] Van Goethem, A., Sloboda, J. (2011). The functions of music for affect regulation. Musicae scientiae, July, 15 (2), p.208-228.

[70] Wojciszke, B. (2000). Postawy i ich zmiana. In J. Strelau (Ed.), Psychologia. Podręcznik akademicki. Tom 3. Jednostka w społeczeństwie i elementy psychologii stosowanej. Gdańsk, Poland: GWP.

[71] Wojciszke, B. (2012). Psychologiczne różnice płci. Wszechświat, 113 (1-3), p.13-18.

[72] Wróbel, M. (2005). Sposoby zmiany nastroju. W poszukiwaniu związku między aktywnością człowieka a samopoczuciem. Psychologia jakości życia, 1 (4), p.89-106.

[73] Zajenkowski, M., Goryńska, E., Winiewski, M. (2012). Variability of the relationship between personality and mood. Personality and individual differences, 52, p.858-861.

[74] Zillmann, D., Bhatia, A. (1989). Effects of associating with musical genres on heterosexual attraction. Communication research, 16, p.263-288.

[75] Zweigenhaft, R. L. (2008). A do re mi encore: a closer look at the personality correlates of music preferences. Journal of individual differences, 29, p.45-55. 